\title{
Correction to: Long non-coding RNAs: implications in targeted diagnoses, prognosis, and improved therapeutic strategies in human non- and triple- negative breast cancer
}

Rubén Rodríguez Bautista ${ }^{1,2}$, Alette Ortega Gómez ${ }^{1 *}$, Alfredo Hidalgo Miranda ${ }^{3}$, Alejandro Zentella Dehesa ${ }^{4}$, Cynthia Villarreal-Garza ${ }^{5}$, Federico Ávila-Moreno ${ }^{6,7}$ and Oscar Arrieta ${ }^{1}$

\section{Correction}

Upon publication of the original article [1], the authors noticed that the Figs. 1, 2 and 3 were incorrectly given. The correct Figs. 1, 2 and 3 are given below.

The original article has been corrected.

\begin{abstract}
Author details
${ }^{1}$ Thoracic Oncology Unit and Laboratory of Personalized Medicine, Instituto Nacional de Cancerología (INCan), San Fernando \#22, Section XVI, Tlalpan, 14080 Mexico City, Mexico. ${ }^{2}$ Biomedical Science Doctorate Program, National Autonomous University of Mexico, Mexico City, Mexico. ${ }^{3}$ Cancer Genomics Laboratory, INMEGEN, Mexico City, Mexico. ${ }^{4}$ Biochemistry Department, Instituto Nacional de Ciencias Médicas y Nutrición Salvador Zubirán, Mexico D.F, Mexico. ${ }^{5}$ Breast Oncology Department, National Cancer Institute of Mexico, Mexico City, Mexico. 'Lung Diseases And Cancer Epigenomics Laboratory, Biomedicine Research Unit (UBIMED), Facultad de Estudios Superiores (FES) Iztacala, National University Autonomous of México (UNAM), Mexico City, Mexico. ${ }^{7}$ Research Unit, National Institute of Respiratory Diseases (INER) "Ismael Cosío Villegas", Mexico City, Mexico.
\end{abstract}

Received: 26 July 2018 Accepted: 26 July 2018

Published online: 08 August 2018

\section{Reference}

1. Bautista RR, Gómez AO, Miranda AH, Dehesa AZ, Villarreal-Garza C, ÁvilaMoreno F, Arrieta O. Long non-coding RNAs: implications in targeted diagnoses, prognosis, and improved therapeutic strategies in human non-and triple-negative breast cancer. Clin Epigenetics. 2018;10(1):88.

\footnotetext{
* Correspondence: ortega.alette@gmail.com

'Thoracic Oncology Unit and Laboratory of Personalized Medicine, Instituto Nacional de Cancerología (INCan), San Fernando \#22, Section XVI, Tlalpan, 14080 Mexico City, Mexico
}

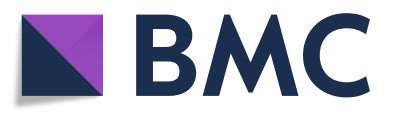

(c) The Author(s). 2018 Open Access This article is distributed under the terms of the Creative Commons Attribution 4.0 International License (http://creativecommons.org/licenses/by/4.0/), which permits unrestricted use, distribution, and reproduction in any medium, provided you give appropriate credit to the original author(s) and the source, provide a link to the Creative Commons license, and indicate if changes were made. The Creative Commons Public Domain Dedication waiver (http://creativecommons.org/publicdomain/zero/1.0/) applies to the data made available in this article, unless otherwise stated. 

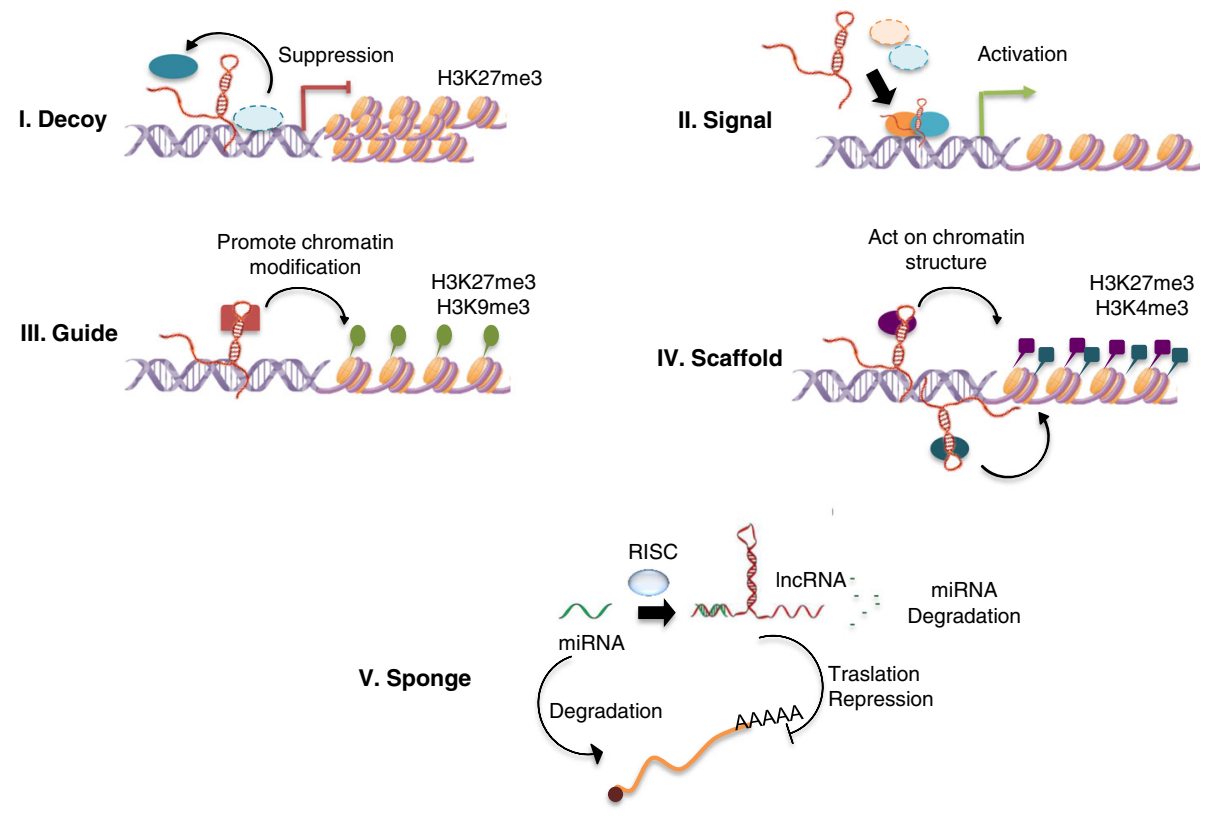

Fig. 1 Proposed five functional archetypes for the IncRNA mechanisms. 1. Decoys: IncRNAs can titrate away transcription factors and other proteins away from chromatin, or titrate the protein factors into nuclear subdomains. 2. Signals: IncRNAs expression can faithfully reflect the combinatorial actions of transcription factors (colored ovals) or signaling pathways to indicate gene regulation by space and time. 3. Guides: IncRNAs may recruit chromatin-modifying enzymes to gene-promoter targets, either in Cis (near the genetic region of the IncRNA transcription) or in Trans into distant target genes. 4. Scaffolds: IncRNAs may bring together multiple proteins to conform ribonucleoprotein complexes. The IncRNA-RNP may act on chromatin as illustrated to affect histone code modifications. In other instances, the IncRNA scaffold is structural and stabilizes nuclear structures or signaling complexes 5. Sponge: IncRNAs that by complementarity of bases succeed in matching or sequestering sequences of small non-coding RNAs, such as miRNAs, are controlling bioavailability of miRNAs, vs. IncRNAs themselves, with the functional biological repercussions at cellular or physiological level. RNA-induced silencing complex RISC 
a lincRNA-RoR as miRNA inhibitor

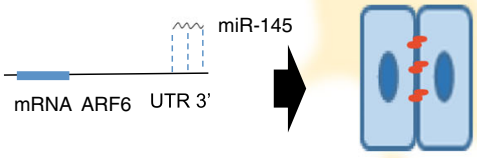

mincRNA-RoR
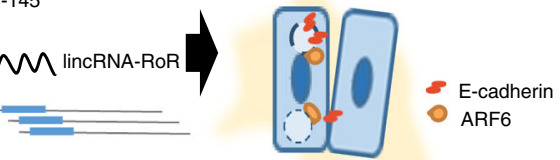

b

competitive endogenous RNAs (ceRNA)

\section{LINK-A as RNP component}
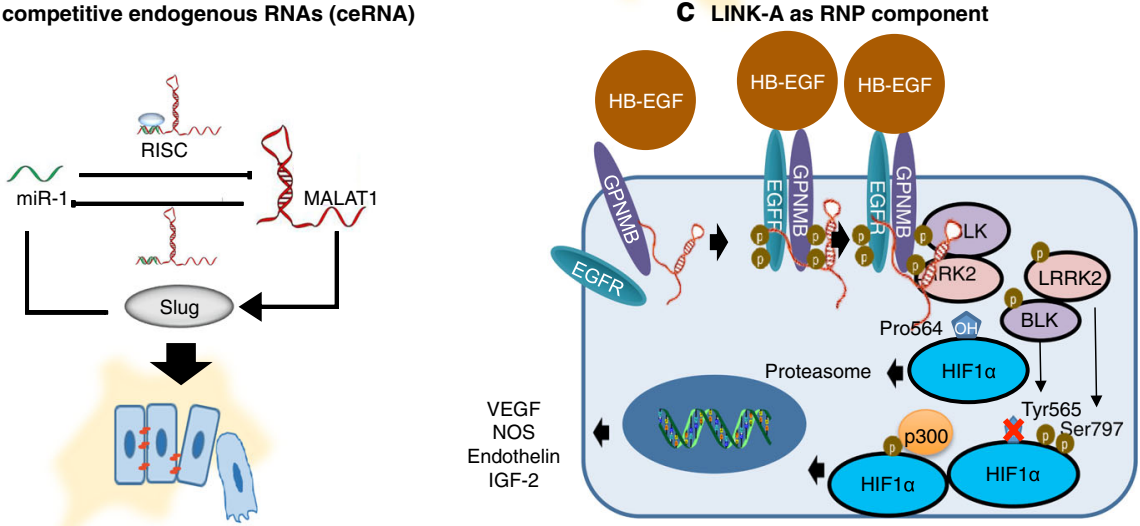

Fig. 2 A molecular mechanism model for IncRNAs involved in the tumorigenesis of human TNBC. a lincRNA-RoR as a miR-145 inhibitor (oncogene miRNA). $\mathbf{b}$ MALAT1 as a competitive endogenous RNA of miR-1 (tumor suppressor miRNA). $\mathbf{c}$ LINK-A as a component of ribonucleoprotein complexes, example shows the regulations of HIF1 a pathway. ARF6 ADP-ribosylation factor 6, UTR 3' untranslated region 3, RISC RNA-induced silencing complex, HB-EGF heparin-binding EGF-like growth factor, EGFR epidermal growth factor receptor, GPNMB transmembrane glycoprotein NMB, BLK B lymphocyte kinase, LRRK2 leucine-rich repeat kinase 2, HIF1a hypoxia-inducible factor 1-alpha, vascular endothelial growth factor VEGF, iNOS inducible nitric oxide synthase, IGF-2 insulin-like growth factor 2, RNP ribonucleoprotein 


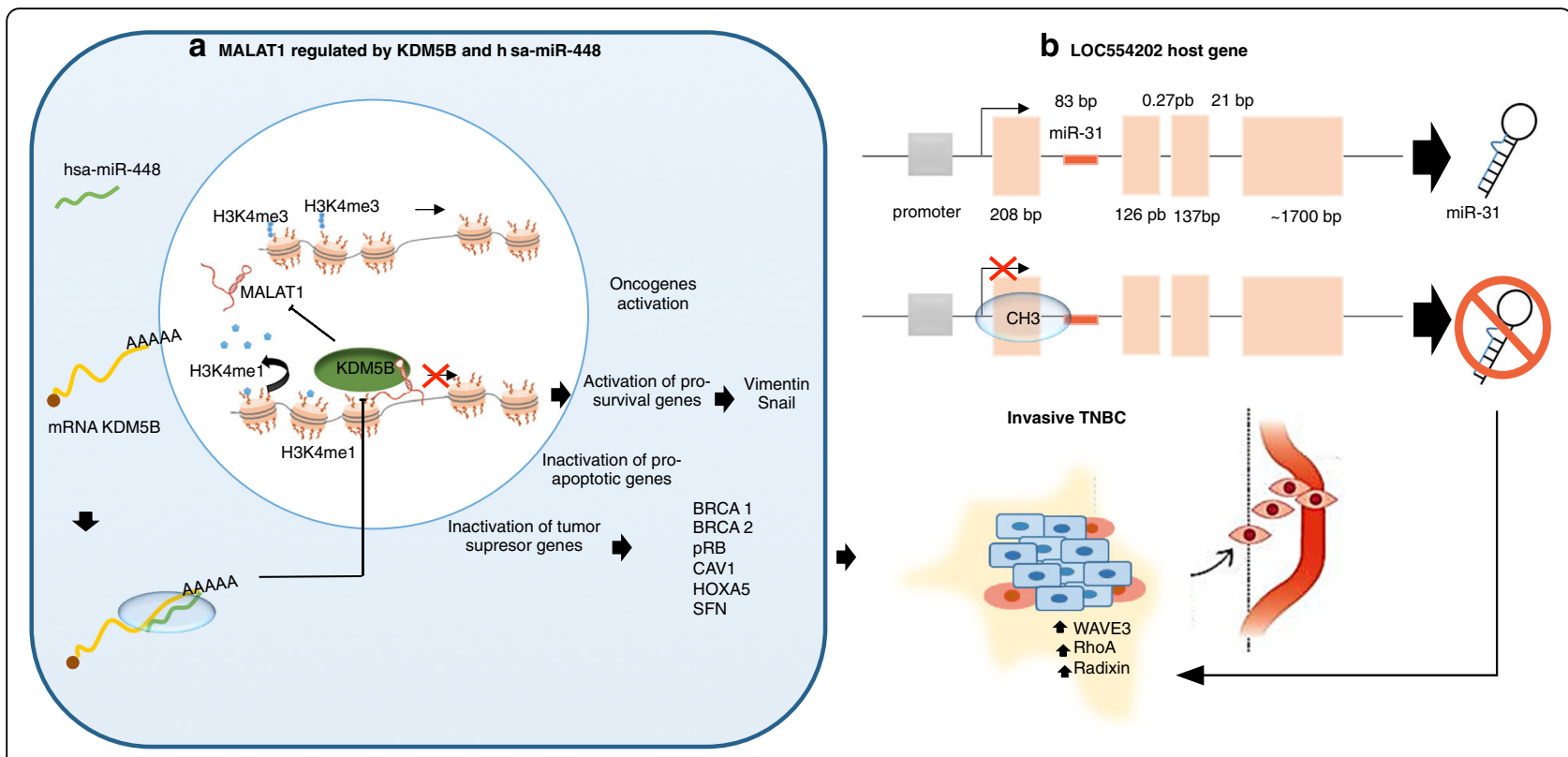

Fig. 3 Epigenetic implications of IncRNAs in the development of TNBC. a MALAT1 regulated by KDM5B and has-miR-448. b LOC554202 as a host gene of miR-31 (tumor suppressor miRNA), WAVE3 (WAS protein family member 3) KDM5B (lysine-specific demethylase 5B also known as histone demethylase JARID1B), H3K4me3 (trimethylation of lysine 4 on the histone $\mathrm{H} 3$ protein subunit), H3K4me1 (monomethylation of lysine 4 on the histone H3 protein subunit), hsa-miR-448 (also known miRNA448), BRCA1/2 (breast cancer 1/2), pRB (retinoblastoma protein), CAV 1 (caveolin 1) HOXA5 (Homeobox protein Hox-A5), SFN (Stratifin), CH3 (methyl group), and RhoA (Ras homolog gene family, member A) 